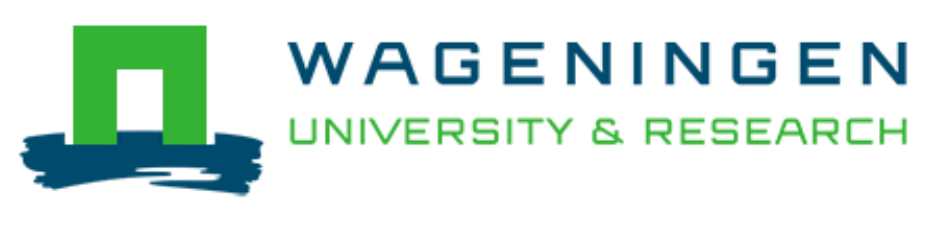

\author{
Special Issue: Christian Philosophical Perspectives on Sustainable \\ Development \\ Massink, H., \& Jochemsen, $H$.
}

This is a "Post-Print" accepted manuscript, which has been published in "Philosophia Reformata"

This version is distributed under a non-commercial no derivatives Creative Commons (c) (1) @ ( 9 (CC-BY-NC-ND) user license, which permits use, distribution, and reproduction in any medium, provided the original work is properly cited and not used for commercial purposes. Further, the restriction applies that if you remix, transform, or build upon the material, you may not distribute the modified material.

Please cite this publication as follows:

Massink, H., \& Jochemsen, H. (2018). Special Issue: Christian Philosophical Perspectives on Sustainable Development. Philosophia Reformata, 83(1), 3-18. DOI: $10.1163 / 23528230-08301002$

You can download the published version at:

https://doi.org/10.1163/23528230-08301002 


\title{
INTRODUCTION
}

\section{Special Issue: Christian Philosophical Perspectives on Sustainable DEVELOPMENT}

\author{
Henk Massink \\ Independent scholar \\ h.f.massink@solcon.nl \\ Henk Jochemsen \\ Wageningen University, Wageningen, The Netherlands \\ henk.jochemsen@wur.nl
}

\section{$1 \quad$ Introduction}

The issue of the survival of the earth as home for mankind is as old as the history of mankind. Several religious traditions contain stories about deities who would like to extinguish human life on earth. This religious message has, in light of the disasters that were taking place, often been combined with the fear that the end of the world was drawing near.

In the last quarter of the nineteenth century we entered a new stage in human history; namely, the period called Anthropocene. The term Anthropocene stresses that in this period the activities of humankind are irreversibly shaping our natural environment. These activities could possibly even result in the extermination of all living creatures on earth—as a consequence of technological developments, or as a consequence of mankind's way of living. The consumption and production patterns of mankind as a whole overload and ultimately destroy the regenerating capacity of the planet. This raises the issue of the earth's long-term regenerating capacity, and, as its flipside, the sustainability of present human existence on earth.

As the short historical overview in section 2 shows, sustainability, as it is commonly used in this context, is a composite concept, composed of economic, ecological, and social issues. It has often been said that, due to its broad and rather ill-defined content, the concept is ambiguous, or even useless. So here we first need to briefly present the debate on the meaning of sustainability (section 2). As a second issue in this introduction, we will consider the question of how to connect the concept of sustainability with a Christian way of doing philosophy, especially the way of Reformational (Dooyeweerdian) philosophy. A typology of various uses of Dooyeweerdian philosophy will be presented in section 3 . We will close this introduction with an overview of the contributions to this special issue, highlighting some notable points.

\section{A History of the Concept and Meaning of Sustainability}


There is abundant literature on the meaning of sustainability, ${ }^{1}$ as well as compilations of definitions of this concept. However, there is still much discussion and misunderstanding due to the lack of clarity about the exact meaning of the concept. To clarify what it means, it is helpful to look at its history.

In 1992, Charles V. Kidd wrote an article about the origin of this concept (Kidd 1992). He made a distinction between different periods in recent history: firstly, the period between World War II and 1972, in which the roots of the concept were defined; secondly, the period between 1972 and 1980, in which the concept emerged and evolved; and thirdly, the period between 1981 and 1988, in which the concept became popular.

Kidd mentions the following six roots of the concept of sustainability: (i) ecological concerns about the carrying capacity of the earth; (ii) the exhaustion of resources; (iii) the impact of human activities, especially industries, on the biosphere; (iv) technology critique; and (v) the no-growth/slowgrowth root. The last two roots are linked to the ecological roots in the sense that implementation of technologies in economic production and strong economic growth are causes of environmental damage. The sixth and last root that Kidd distinguishes brings together the earlier-mentioned roots. Adding more explicitly the societal dimension, Kidd speaks about (vi) the ecodevelopment root, which he defines in the words of Ignacy Sachs as "an approach to development aimed at harmonizing social and economic objectives with ecologically sound management, in a spirit of solidarity with future generations" (Kidd 1992, 12).

Kidd's sixth root already refers to the content of the later concept of sustainability. The first mention of the word sustainable can be found in Edward Goldsmith and Robert Allen's A Blueprint for Survival, published in 1972: this book does not use the substantive sustainability but the adjective. In the same year, the International Union for Conservation of Nature mentions the adjective sustainable in its yearbook. The first time sustainability was mentioned as a substantive in the context of the United Nations was in 1978, when the United Nations Environment Program stated that "sustainable development means that the needs of present and future generations must be appropriately reconciled.” Kidd $(1992,18)$ concludes that “"sustainability' emerged in the context of broad social, economic, and political goals, rather than in the context of more narrowly defined resource management and ecological concepts.”

From the beginning, the churches joined the debate on sustainability (see also the papers of Northcott and Jochemsen in this issue). Already in 1974, the World Council of Churches organized a conference in Budapest where the term sustainability was used. Nine years later, the World Council of Churches started the conciliar process: a process for justice, peace, and the integrity of creation. This third value was especially linked to environmental issues. Although many people see the conciliar process as basic for the engagement of churches with environmental issues today, theologically orthodox churches may have considered the issues of environment, justice, and peace as being closely connected with left-wing politics. This perceived connection prevented them from recognizing the relevance of environmental issues (cf. Jochemsen's contribution to this special issue).

In the third period (1981-1988) mentioned above, sustainability became a popular concept. The publication of the Brundtland report (1987) can be seen as a milestone in the history of this concept. It comprises not only ecological goals, but also social, economic, and political goals, connected to an intragenerational and intergenerational perspective. According to the Brundtland Commission, sustainable development is "development which meets the needs of current generations without compromising the ability of future generations to meet their own needs." Since then, this definition has been widely accepted and used in policy and business circles. From a systematic and

\footnotetext{
${ }^{1}$ See Massink (2013, 14n14) for various references to this literature. See also Massink’s 2013 book (in Dutch) for an extensive description of the history of the development and use of the concept of sustainability.
} 
scientific point of view, we would like to make a few observations regarding this definition (Kidd 1992, 21).

As already indicated, the Brundtland report has been the point of reference and the conceptual basis for the political debate on sustainability since its publication. It was the starting point for Agenda 21, a major result of the Earth Summit which took place in Rio de Janeiro in 1992. A comprehensive agenda for sustainable development, Agenda 21 was the translation of the Brundtland report into an action plan (Adams 2009, 90-95), and it laid the foundation for the summits which were organized in 2002 (Johannesburg top meeting) and in 2012 (Rio+20).

A totally new phase in the multilateral debate on sustainable development started in 2015. In that year the Paris Declaration on Climate was accepted, and the UN General Assembly accepted the 17 sustainable development goals (SDGs) - these follow up the millennium development goals (MDGs), which expired in 2015. In September 2015, all countries of the world declared in New York that they were willing to implement Agenda 2030 in their national policies. In the implementation of these goals, the entire society-businesses, knowledge institutes, non-governmental organizations, etc.) should participate.

The essence of the concept of sustainability, or sustainable development, is the conceptual combination of economic development with social and ecological issues. Developments in these three dimensions should take place with special attention for the interrelations between the three. This is made explicit in the phrase triple p bottom line—i.e., people, planet, and profit—coined by John Elkington in 1994 and used in his book Cannibals with Forks. The Triple Bottom Line of 21th Century Business. Elkington operationalized the concept of sustainability for business as corporate social responsibility (Elkington 1999).

The views of Kidd and Elkington show that many systematic philosophical questions can be raised regarding sustainability. For example, how can three different dimensions, representing different types of values, be combined within one concept, let alone measuring progress in these three dimensions? Connected to this issue is the weighing of the different dimensions. The debate between strong sustainability and weak sustainability is an example of such a systematic question (Norton 2005, 310-316). Another question is which issues belong to the concept of sustainability and which do not. Has animal welfare anything to do with the survival of the earth? Do social issues, as such? Is it not (theoretically) thinkable that, when less attention is paid to animal welfare and the poor, the earth's ecosystem's chances of surviving improve?

Another systematic point in addition to, and directly connected with, the question of the scope of the sustainability concept is the question of normativity. According to Kidd, some people believe that sustainability, in its broad meaning, is too broad and value-laden; they prefer a closer definition with value-free ecological terms (Kidd 1992, 23). What happens if we also take into account the social dimension of sustainability? Will it only then become a normative concept? What kind of normativity is this? And are the ecological and economic dimensions free of normativity? In our view, all three dimensions of sustainability are necessarily normative.

In this introduction, we will not present a full discussion on the first series of questions regarding the scope of the concept-we accept the broad definition of the Brundtland report as a good working definition. We will discuss the questions concerning value-ladeness; these provide us with an opportunity to explore the relation between normativity and sustainability. We will describe in the following section the different angles which can be used to address the normativity of sustainability from a Christian philosophical perspective.

\section{$3 \quad$ Reformational Philosophy and Sustainability Issues}




\subsection{The Relevance of Dooyeweerdian Philosophy for Reflection on Sustainability}

There are several reasons to draw on the philosophy of Herman Dooyeweerd and Dirk Vollenhoven in our analysis of the meaning and use of the sustainability concept. The first reason is the concept's multidimensionality - multidimensionality is an important characteristic of Dooyeweerd and Vollenhoven's philosophy. As indicated above, the definition of Brundtland has been made operational in three dimensions, namely, the ecological, the economical, and the social. Dooyeweerd distinguishes 15 dimensions in reality, which he calls modal aspects.

Connected to this similarity in multidimensionality, adherents of sustainability and Dooyeweerdian philosophers both aim to relate different dimensions to each other. The purpose of using a multidimensional concept of sustainability is to reach harmony or a state of weighed equilibrium between economical, ecological, and social values. The same can be said of Dooyeweerdian philosophy: it aims to stress the importance of a balanced view of reality without absolutizing or neglecting any of its aspects.

In addition to these similarities, there are other reasons why it can be fruitful to use a Dooyeweerdian approach. Dooyeweerdian philosophy presumes that normativity is inherent in created reality, and it seeks to identify that normativity and its influences on our theoretical understanding of the world, as well as examine the way we relate to our natural and cultural environment.

Finally, Dooyeweerd developed a well-elaborated vision on cultural development. And in the societal debate on sustainability, we also speak about the development of society, especially in regard to how we hand down our society and planet to future generations. From this perspective, there is a close connection with philosophy of culture.

\subsection{Applications of Dooyeweerdian Philosophy to Sustainability}

Extensive research has been conducted on the application of Dooyeweerdian philosophy to sustainability issues. We will present a brief overview.

\subsubsection{The Cultural-Philosophical Approach}

In the Dutch tradition of Reformational philosophy, two scholars stand out with regard to the culturalphilosophical use of Dooyeweerd. The first is Bob Goudzwaard, who criticizes the dominance of capitalist economic thinking in our Western culture. The other is Egbert Schuurman, who focused during his entire academic and political life on the tremendous influence of technology on society, in connection with a neoliberal economic motive. Both Goudzwaard and Schuurman have used ideas of Dooyeweerd in pointing out the dominance of some societal sectors over others. Put in terms of normativity: the way in which societal sectors or values are related to one another depends on political and ethical views that are ultimately based on a person's worldview.

Behind this view of normativity in reality lies a strong Dooyeweerdian critique of Western theoretical thinking in the tradition of the Enlightenment (Kant). In contrast to the Enlightenment view, Dooyeweerd points to the intrinsic normativity of our theoretical thinking itself, which is ultimately based on a religious starting point. In Dooyeweerdian philosophy, thinking starts in a given world and is always secondary to our daily experiential and holistic way of knowing. This leads to a totally different view on mankind's relation to the rest of creation. According to Dooyeweerd, humans should not pursue knowledge of reality in order to gain control over it and to use it for their own interests - rather, their pursuit of knowledge should have its point of departure in the acknowledgment of the existence and value of things in their own right, especially the earth and all its plants and animals. 


\subsubsection{Criticizing the Subject-Object Split in Western Philosophy and Culture}

The cultural-philosophical perspective can be deepened with reference to the typical Western way of looking at reality which has become dominant since the switch to subjective rationalism in the philosophy of Descartes-the process called modernization. It concerns the question of how we position ourselves as human subjects over against the reality surrounding us. In its core, modernity can be understood as a change in the relationship between mankind and reality. In premodern cultures, both in Europe and in other parts of the world, physical reality and spiritual reality are seen as closely related and interconnected. In the process of (European) modernization, physical reality was conceptualized as separated from spiritual reality. In addition, man's relation with physical reality became increasingly characterized by objectification and rational reasoning. This new relationship became the center of modern science, which in its turn influenced the way people in general related to physical reality. No longer regarded as a divine creation or a divine cosmos harbouring an intrinsic normativity, in the modernist approach the world is seen as value-free matter that can be used as raw material for the technological (re)construction of the world according to mankind's own views (Jochemsen 2015). Hence, in Dooyeweerdian thinking, the subject-object split in Western culture is considered one of the roots of the ecological sustainability issue. This view can be identified in the contributions of Verkerk et al. and of Rademaker and Jochemsen.

\subsubsection{Dooyeweerdian Multi-aspectuality of Reality: Practical Use}

Within the Reformational philosophical tradition, Andrew Basden in particular has contributed directly and indirectly to the application of Dooyeweerdian philosophy to sustainability. He describes the relevance of Dooyeweerdian philosophy as follows (Basden 2013):

Sustainability is a major possible application area for Dooyeweerdian philosophy, especially his notion of irreducible aspects. It might be able to offer us:

- $\quad$ a principled understanding of sustainability

- $\quad$ a conceptual tool by which to manage, predict, plan for and evaluate sustainability.

It recognises the special nature and responsibility of humankind while seeking holistic balance with all the Creation.

A professor at the University of Salford, Basden stimulated colleagues to operationalize the philosophy of Dooyeweerd. ${ }^{2}$ The work of Patrizia Lombardi needs special reference here. With her $\mathrm{PhD}$ supervisor Peter Brandon she wrote a book entitled Evaluating Sustainable Development in the Built Environment (Brandon and Lombardi 2005). In this work, the authors explain how the philosophy of Dooyeweerd, especially the doctrine of modal aspects, can be employed in an evaluation of the sustainability of the built environment, using the 15 aspects as a checklist of relevant issues and connected values. The work of Brandon and Lombardi was so fruitful that it has been further developed and is used extensively by scholars all over the world for urban and rural planning.

The authors of the Salford school of thought are aware of the existence of other elements in the theory of modal aspects, of which they only use certain parts. Different scholars elaborate to some extent different elements of Dooyeweerd's theory of reality. For instance, Brandon and Lombardi take into account the foundational relation of earlier aspects to the later ones. Manila de Iuliis, who builds on the work of Brandon and Lombardi, elaborates the Dooyeweerdian philosophy of time for the sustainability of the built environment. Han Vandevyvere stresses other elements of the

\footnotetext{
${ }^{2}$ For a full treatment and discussion of the Salford school of thought, see Massink (2013, 185-192).
} 
Dooyeweerdian theory of reality: he refers to the meaning kernels in the different aspects, which come back analogically in other aspects. This brings him to the conclusion-fully in agreement with Dooyeweerd - that noneconomic values cannot be expressed in terms of economic values because the two are basically incomparable (Vandevyvere 2010, 113-114).

\subsubsection{Other Usage of the Multi-aspectuality of Reality: Business Related to Sustainability} (Corporate Social Responsibility)

There are various other examples of the application of Dooyeweerdian philosophy to sustainability issues (see Massink 2013, 192-196). Related to the concept of sustainability is the concept of corporate social responsibility (see section 2), which refers to the responsibility of companies for societal issues in the social and environmental sphere. Reformational philosophers Maarten Verkerk and Arthur Zijlstra have taken a further step in the application of Dooyeweerd's theory in their work on the normative responsibility of companies (Verkerk and Zijlstra 2003). They distinguish between the different entities within a company - the production unit, the communication unit, the management unit, the research and development unit, and the sales unit—each of which has its own qualifying function. The production unit can be further subdivided into a production unit (the production process as such), a control unit, and an information unit. Henk de Vries had previously distinguished between the community of production employers (social), the company as enterprise (economic), and the company as production process (technical) (De Vries 1999).

Zijlstra and Verkerk applied their analysis to the issue of corporate social responsibility. Thus, they consider the company an economic entity, and correctly so, because it is qualified by the economic function, which discloses the way in which the social and ecological dimensions are implemented. With the social and ecological issues subordinated under economic goals within the borders of a company, several systematic questions arise. For example, what happens to this order when the company is viewed in a broader context of national and international legislation-e.g., with respect to greenhouse gas emissions? Will the economic function in that context continue to be qualifying (that is, leading)? It would appear as if the juridical conditions take over the lead. One could also argue, however, that, although legislation provides strict boundary conditions to the functioning of the company, at the end of the day, the company must be able to function economically. In other words, as long as a company continues its activities, the economic function is leading.

\subsubsection{Normative Practices: Using Structural Analysis to Denote Virtues as Guiding Values} Reformational philosophy has often been criticized for its lack of practical application modes. In other words, there is no direct connection between thinking about the nature of reality and our way of acting in this reality. From 1995 onwards, partly as a reaction to this type of criticism, some Reformational philosophers have developed the theory (approach) of normative practices. On the one hand they founded this theory on Alisdair MacIntyre's idea of a normative practice, whereas on the other hand they used Dooyeweerdian philosophy in the elaboration of the concept of a normative practice. For MacIntyre, a practice is inherently shaped in a specific way and oriented to a specific goal, independent of personal human preferences. MacIntyre's view of practices is closely related to virtue ethics: in order to perform a practice well one needs certain virtues. At the same time, by realizing this practice, the practitioner exhibits certain societal virtues and realizes the related values. In this sense, a practice holds an intrinsic normativity. In terms of Dooyeweerd's structure theory, a normative practice ought to be seen as an individuality structure. In this sense, a normative practice can be treated the same way as, for example, an association or any other social entity. ${ }^{3}$

\footnotetext{
${ }^{3}$ See Philosophia Reformata vol. 82 (2), a special issue on normative practices in which the normative practice model is explained and applied to a number of practices.
} 
The question arises whether it is possible to use the concept of normative practices as a way of elaborating individuality structures, to evaluate whether a certain practice is sustainable. Is a fisherman or a farmer who performs his/her practice according to the normative structure as described by the normative practice approach (NPA) by definition a sustainable fisherman or sustainable farmer? If the NPA is in fact also a description of a sustainable practice, the economic, ecological, and social dimensions should strike a balance.

Let us take the farmer's practice as an example. First, we need to identify its qualifying aspect. What is the main task of a farmer-is it caring for nature, or producing food, or earning money? Most farmers nowadays are seen as entrepreneurs: they try to earn a living by producing food. In that case, the economic aspect is qualifying. But in his practice the farmer has to respect the quality of soil and water, consider animal welfare, and conserve biodiversity and landscape. The social aspect of farming can refer to the treatment of the farmer's employees, his/her dealings with suppliers and customers, and the way in which the farmer lives together with neighboring farmers and other citizens. Another issue which belongs to the social aspect is the farmer's relation to his/her colleagues in other parts of the world. Would observing all these normative aspects indicated by the NPA result in sustainable farming? Or would the NPA require giving priority to the qualifying economic aspect of the farm, at the expense of, for example, the sensitive and ethical aspects regarding animal welfare, since otherwise the economic sustainability would become threathened?

We will not elaborate this here; rather, we will briefly comment upon the application of the NPA to the issue of sustainability. The use of the NPA to evaluate a practice's sustainability concerns in the first place the level of the primary practice itself-here, the practice of farming. But in many cases, and certainly in the case of farming, practices are embedded in a societal, economic, and political structure-not only on a regional and national level, but also on a continental and global level. On the one hand, these structures enable the primary practice; on the other hand, they can also frustrate frustrate a performance in which the intrinsic normativity is observed." This means that in order to achieve sustainability, the system as a whole — in the case of farming, primarily the food system — should respect normative points of view of practices at the various levels of global structures (see Rademaker and Jochemsen's contribution to this issue, as well as Rademaker, Glas, and Jochemsen [2017] ).

\subsection{Preliminary Conclusions}

We agree with Kidd (1992) that the sustainability concept is complicated by problems- to wit, the broadness of the concept and its value-ladenness. The concept is broad and comprehensive, including economic, ecological, social, and sometimes political values, such as peace and justice. This broadness is a direct consequence of the concept's core elements, namely, the future of human life on a liveable planet and the distribution of welfare among peoples and nations.

The value-ladenness, or normativity, of the concept directly relates to its described broadness. Above, we have briefly indicated how the philosophy of Dooyeweerd, which aims to explain and identify both the normativity of reality and our theoretical knowledge of this reality, can be helpful in elucidating the pivotal normative points in the concept of sustainability and its applications.

In the subsections 3.2.1 - 3.2.5 we described different angles on discovering this normativity. Most of them have to do with the relative weight of value domains. So, it is not surprising that several authors in the Reformational philosophical tradition spoke about the simultaneous realization of norms (derived from the various aspects) - there is no reduction of one aspect of reality to another, and there is no performance focussing on one aspect to the detriment of another. But what does this mean in daily practice? This approach does not lead to exact criteria and boundaries (for which detailed knowledge pertaining to the different normative aspects in which the practice functions is required). But this approach can be used very well in a hermeneutic sense, at different societal levels: it can be used, for example, in order to determine which values are at stake in a certain concrete issue-e.g., the construction of a motorway - or to determine what normative points of view must be taken into 
account in policy with respect to agriculture both at a national and international level. An example of such a special use of the NPA can be found in the contribution of Verkerk et al. in this issue.

\section{$4 \quad$ Introducing the Papers in This Issue}

Not all articles in this special issue are directly concerned with the philosophy of Dooyeweerd and Vollenhoven. The authors of the first two contributions discuss the important issue of the relation between Christian faith and environmental damage. Did Christianity induce a culture that disregards care for the environment, due to its position on the dominion of man over the rest of creation (Gen. 1:26-28)? The thesis that the disastrous record of Western civilization with respect to environmental care is due to Christianity's anthropocentrism has been explicitly defended by Lynn White.

Michael Northcott's remarkable and valuable paper disagrees with this thesis, arguing that especially Protestantism has given rise to movements defending nature conservation and care for creation, much more than other strands of Christianity or Asian religions. He identifies important roots of this concern for nature in the Protestant romantics' fascination with nature, in particular wilderness, as having redemptive power: as the "original book of God's works," it shows the work of the Creator. He goes on to outline various characteristics of Protestantism that can help explain the historic association between Protestantism and the concern for nature; for example, "the Protestant recovery of the religious power of biblical literature and the influence of biblical nature imagery and poetry as source for romantic and modern appreciation of nature." Another characteristic is the new emphasis that Protestantism put "on personal experience, on feelings, and on reason, as constitutive components of the Protestant self, and of the ways towards the moral and spiritual formation of the self." This in turn led to new ways of seeking to form and redeem the self- in nature, among other things. Finally, Northcott mentions the Protestant promotion of democracy, state of law, and justice, including social and environmental justice.

The idea that a full concept of justice should include environmental justice comes back in several papers in this issue-for example, in Henk Jochemsen's contribution. In his response to Northcott, Jochemsen begins by expressing his appreciation of Northcott's main point. But according to Jochemsen, in a discussion on the role of Protestantism in environmentalism, we should do more than point out the relatively positive role of Protestants. On the basis of relevant literature, Jochemsen maps out a diversity of attitudes of Christians - including Protestants, in a broad sense. Within twentieth-century Protestantism, both a positive and a negative attitude towards environmentalism can be found. Generally speaking, the concern for nature and the environment has been stronger in mainstream, ecumenical, and liberal strands of Protestantism than in theologically more conservative strands (although these are currently catching up). An important background of this phenomenon is that Protestantism has associated itself with modernity's emphasis on economic growth as expression of mankind's stewardship over creation. This economic growth, however, was obtained at the expense of natural resources and the care for nature. Read together, Northcott's and Jochemsen's papers provide an interesting and broad reflection on the role of protestant Christianity in environmentalism, though some remarks are made on other parts of Christianity.

The article of Steven van den Heuvel discusses Pope Francis's view on the future of our planet as expressed in his encyclical Laudato Si'. In examining the ideas of Pope Francis, Van den Heuvel refers to mankind's special position in creation and the mandate that God has given to man. In his opinion, the pope does not clearly recognize the anthropocentric notion of this mandate. In discussing 
this issue, Van den Heuvel delivers an important contribution to the debate on such questions as to whether Christianity is anthropocentric or biocentric and what may be the consequences of such positioning. He further argues that the pope's arguments for a theocentric approach instead of an anthropocentric or a biocentric approach are debatable. In spite of his critique, however, Van den Heuvel also expresses his appreciation of this important ecclesiastical contribution to the sustainability debate. Laudato Si' is influential because the Roman Catholic Church is represented on all continents. This is important since sustainability issues are planetary issues. With the contribution of Van den Heuvel, the scope of this special issue is broadened from the Protestant to the Roman Catholic tradition and its thinking about environmental issues.

The article of Ben-Willie Kwaku Golo broadens the scope even further. He connects thinking about the sustainability of developments on the African continent with aspects of justice, righteousness, and peace. In our view, he rightfully does not isolate environmental issues from other societal and international issues: issues of climate change, poverty, migration, violence, etc., are interlinked. (Environmental) justice is needed and requires global awareness of responsibility for each other. This well-informed perspective from the Global South bears the mark of some of the movements within Protestantism indicated by Northcott and Jochemsen-particularly, the movement in ecumenical circles emphasizing a sustainable community and favoring a broad concept of justice, including both social and environmental justice. The church in the Global South suffers severely from both social and environmental injustice, and people are well aware of their interconnection. The need for global awareness of mutual responsibility among people all over the globe and for creation at large can also be identified in the sustainable development goals of Agenda 2030. These SDGs stand for people, planet, and prosperity (the original triple p), but also for peace and partnership. Such an approach fits very well in the integral understanding of reality in Reformational philosophy as explained above.

In the contribution of Maarten Verkerk, Paolo Ribeiro, Andrew Basden, and Jan Hoogland, the three dimensions — to wit, economic, ecological, and social—of the mainstream concept of sustainability come together in their study of a future electricity infrastructure. Due to an enormous diversity of producers and kinds of ways to produce electricity, that future system will be highly complex. The authors' central questions are how to fundamentally understand that complexity and how to guide the development of this infrastructure in view of its size, interoperability, and complexity. Although Verkerk et al. do not elaborate it, we believe these questions are closely connected to the need to find a more ecologically sustainable way of producing and using energy. The electricity infrastructure of the future should be economically sustainable; it should also be ecologically sustainable, in view of the relation between fossil energy and climate change; and it should be socially sustainable, for society to a large extent depends on this form of energy. Drawing on the NPA to come to a better normative grasp of the system, Verkerk et al. use a typical element of Dooyeweerdian thinking that is not often used in the NPA, namely, the concept of enkapsis.

After discussing various types of enkapsis that Dooyeweerd distinguished, the authors add a new type to the list, which they call network enkapsis. They feel the need for this philosophical innovation in order to better deal with the complexity of the system under study, and we applaud their courage and creativity. Their proposal may raise the question of whether it is a disclosing or perhaps (also) a foreclosing innovation, and we would encourage that discussion. Whatever the outcome of that discussion may be, the proposal of Verkerk et al. demonstrates that doing philosophy along Dooyeweerdian lines continues to introduce new ideas and approaches to improve our understanding of developments and phenomena in our increasingly complex society.

In this issue’s final paper, Corné Rademaker and Henk Jochemsen seek to identify the normativity that should be respected in development cooperation. They argue that the modernist roots of today's concepts of development are hindering the elucidation of an adequate ethics for cooperation 
in development, because a modernist approach denies, or at least neglects, the inherent normativity of reality. It is true that empirical reality is not in itself the standard for what is good. But that does not mean that some conditions do not support human flourishing much better than other conditions. Identifying those favorable conditions is a task for ethics. Rademaker and Jochemsen contend that the NPA helps in identifying those conditions, and they argue at length about the question whether development cooperation really is a practice, and if so, what its qualifying function should be. They conclude that, even though development cooperation is not an easily defined practice, the work of development professionals has many characteristics of a normative practice. Typical of that practice is the interlinking and unfolding of a diversity of practices—each with its own type of normativity - in the developing society, whose well-functioning embodies development in the normative sense. This leads to the conclusion that the development cooperation practice is qualified by the formative aspect and cannot exist without the facilitated practices. This approach prevents development cooperation from becoming too narrow—e.g., focusing mainly or exclusively on economic development—or too paternalistic.

\section{$5 \quad$ Concluding Remarks}

In this special issue of Philosophia Reformata, a number of articles are published that were originally papers presented at the international conference "Christianity and the Future of Our Societies" held in Leuven in August 2016. These contributions treat with issues concerning sustainability and development, in which development should be understood in a broad sense and not only as development in so-called developing countries. The problem of sustainability is global and is discussed as such.

All contributing authors approach their topic from a Christian (philosophical) perspective, while several articles have also included theological input. These papers clearly demonstrate that Christian thinking can significantly contribute to policy making and reflection on the urgent issue of sustainability in a world that seems to be dominated by economy and technology. The unmasking of these two - and other-idols is a first step towards effectively dealing with issues of sustainability in at least the ecological, social, and economic sense, and working towards a more sustainable and juridically and ethically just society. Philosophy in the school of Dooyeweerd helps us to identify the cultural and philosophical roots of our societies' unsustainable character, and to provide concepts and insights to propose normative approaches in order to deal with the resulting issues. From the various contributions it is also clear that there are no simple solutions. This does not mean, however, that we lack all orientation regarding where to begin dealing with these problems: Christianity can make a fruitful contribution towards a more positive future of our societies. ${ }^{4}$

\section{References}

Adams, W.M. (2009). Green Development. Environment and Sustainability in a Developing World. $3^{\text {rd }}$ ed. London: Routledge.

Basden, A. (2013). Environmental and Community Sustainability: A Dooyeweerdian Perspective. The Dooyeweerd Pages, September 5. http://dooy.info/using/sust.html.

Brandon, P.S., and Lombardi, P. (2005). Evaluating Sustainable Development in the Built Environment. Oxford: Blackwell.

\footnotetext{
${ }^{4}$ We would like to extend our thanks to Mathanja Berger for editing the text.
} 
De Vries, H.J. (1999). Kwaliteitszorg zonder onbehagen. Praktische adviezen voor gebruik van ISO 9000 als uitkomst van een christelijk-filosofische analyse. Amsterdam: Buijten \& Schipperheijn; Rotterdam: Instituut voor Kwaliteit, Duurzaamheid en Innovatie (KDI).

Elkington, J. (1999). Cannibals with Forks. The Triple Bottom Line of 21th Century Business. Oxford: Capstone.

Goldsmith, E., and Allen, R. (1972). A Blueprint for Survival. Harmondsworth: Penguin.

Iuliis, M. De (2010). A Dooyeweerdian approach to time in sustainable development, $\mathrm{PhD}$ dissertation , University of Salford.

Jochemsen, H. (2015). Modernization and Environmental Problems: How to Avoid the Pitfalls. In: A. Martinelli and C. He, eds., Global Modernization Review. New Discoveries and Theories Revisited, London: World Scientific, pp. 221-229.

Kidd, C.V. (1992). The Evolution of Sustainability. Journal of Agricultural and Environmental Ethics 1 (5), pp. 1-26.

Massink, H. (2013). Blijvend thuis op aarde? Een historisch, systematisch en praktisch onderzoek naar de mogelijkheid van de operationalisering van het concept duurzaamheid, in het bijzonder voor de landbouw. Delft: Eburon.

Norton, B.G. (2005). Sustainability. A Philosophy of Adaptive Ecosystem Management. Chicago/London: The University of Chicago Press.

Rademaker, C.J., Glas, G., and Jochemsen, H. (2017). Sustainable Livestock Farming as Normative Practice. Philosophia Reformata 82 (2), pp. 216-240.

Vandevyvere, H. (2010). Strategieën voor een verhoogde implementatie van duurzaam bouwen in Vlaanderen. Toepassing op het schaalniveau van een stadsfragment. PhD dissertation, Katholieke Universiteit Leuven.

Verkerk, M., and Zijlstra, A. (2003). Philosophical Analysis of Industrial Organisations. Philosophia Reformata 68 (2), pp. 101-122.

Whyte, L. (1967). 'The Historical Roots of Our Ecological Crisis' in: Science 155, pp. 1203 - 1207.

World Commission on Environment and Development (1987) Our Common Future, Oxford, New York: Oxford University Press. 